\title{
The Effect of Cold Compress 15 Minutes on Delayed Onset Muscle Soreness
}

\author{
Bambang Trisnowiyanto \\ Departement of Physiotherapy \\ Health Politechnic of Surakarta \\ Surakarta, Indonesia \\ btrisnowiyanto@gmail.com
}

\author{
Mustofa Bayu Nirwana \\ Departement of Physiotherapy \\ Health Politechnic of Surakarta \\ Surakarta, Indonesia
}

\begin{abstract}
Delayed onset muscle soreness (DOMS) is an uncomfortable sensation or pain in the muscles after 12-24 hours of high-intensity physical activity, mainly dominated by eccentric and isometric muscle contractions. DOMS will physiologically disappear by itself. If the inflammatory process does not go well, it can result in ongoing injuries that affect body movement and function, so it is necessary to provide interventions to overcome DOMS. Based on studies, ice packs are an effective form of cold therapy to treat DOMS. The purpose of this study was to determine the effect of a cold compress with a duration of 15 minutes on reducing DOMS pain in the gastrocnemius muscle. This research is an experimental study with a one group design with control pre and post-test design. The results of the repeated measures anova test showed a significant reduction in DOMS pain at 24 hours and 48 hours after the treatment in the experimental group ( $p$-value $=0,000)$. It also happened in the control group (p-value $=0,000$ ). The differences effect of pre and post-test $I$ in the experimental group showed a mean value of 11,667 , while the control group showed a mean value of $-10,333$. The results of the one-way anova test showed that there were differences between the experimental group and the control group in post-test $I$ (p-value $=0.000$ ) and no differences between groups in post-test II (pvalue $=\mathbf{0 . 4 3 8}$ ). The conclusion of this study is that a cold compress with a duration of $\mathbf{1 5}$ minutes has a significant effect on reducing DOMS pain.
\end{abstract}

Keywords - cold compress, 15 minutes, pain, delayed onset muscle soreness

\section{INTRODUCTION}

Delayed onset muscle sorenesss (DOMS) is a subjective sensation of discomfort or pain in the muscles that is felt after 12-24 hours of high-intensity physical activity (Zondi et al., 2015). Physical activity, which is dominated by eccentric and isometric muscle contractions is more at risk of causing DOMS. Both types of contractions have an impact on muscle damage resulting in an inflammatory response and induce DOMS pain (Cheung et al., 2003). The intensity of pain increases when stretching or pressing on the muscle belly (Centro et al., 2016).
In the first 6-12 hours, muscle cells damage that produce reactive oxygen active (ROS) and damage associated molecular pattern (DAMP) (Ma et al., 2013; Janssen \& Henson, 2014). DAMPs and ROS stimulate the cytokines TNF, IL-1, and NGF to induce an inflammatory response at 12-72 hours. The inflammatory process will induce DOMS pain in dynamic pain intensity (Seong, 2004). Pain intensity increases physiologically in the first 24 hours, reaches a peak between 24-72 hours, decreases and disappears within 5-7 days after exercises (Veqar, 2013; Murray \& Cardinale, 2015).

Physical activitie, which is dominated by eccentric and isometric muscle contractions include (1) going up and down stairs, (2) going up and down while running, (3) ballistic stretching, (4) cycling with heavy weights, (5) and others (Cheung et al., 2003; Contrò et al., 2016). The muscle most at risk for DOMS is the gastrocnemius muscle (Mirawati et al., 2018). The function and role of the gastrocnemius muscle is as a mover of the lower leg, especially in movements that require strength, speed, and explosive power, as well as as a support for the body during activities. Based on the type of contraction, the gastrocnemius muscle is dominant in the type of eccentric and isometric contraction. This increases the risk of experiencing DOMS so that it is more susceptible to DOMS (Hall, 2016).

DOMS pain intensity will physiologically disappear by itself. But there are things that must be considered, when the inflammatory process does not go well, the acute phase can turn into a chronic phase, causing ongoing injuries that affect body movement and function (Hwang et al., 2019). This can be avoided by providing interventions to treat DOMS, including pharmacological therapy (NSAIDs), massage, electrical stimulation, heating, stretching, and cold therapy (Malmir et al., 2017;Contrò et al., 2016).

Cold compress with ice pack is one of the modalities in the form of effective cold therapy to treat DOMS, which is given to get local effects on body parts (Hohenauer et al., 2015). Cold compresses applied for 10-20 minutes at a temperature of 3-7 ${ }^{\circ} \mathrm{C}$ affect body temperature up to $0-25 \mathrm{~mm}$ under the skin locally 
(Enwemeka et al., 2002). Physiological effects of cold temperatures on tissues, among others, will result in a decrease in excitatory threshold, arteriolar vasoconstriction, decreased nerve conductivity, reduced inflammatory mediator transport, reduced edema, and decreased local temperature of injured tissue. This tissue response will reduce DOMS pain (Malanga, 2015; Bruno et al., 2016).

The researcher intends to conduct a study with the aim of knowing the effect of an ice pack with a duration of 15 minutes on reducing DOMS pain in the gastrocnemius muscle.

\section{METHODS}

This research is an experimental methods with a one group research design with control pre and post test design which was carried out in January to February 2020 at the Health Polytechnic of Surakarta. This study aims to determine the effect of a cold compress with ice pack for 15 minutes on reducing DOMS pain in the gastrocnemius muscle.

The population of this research subject is physiotherapy students. The inclusion criteria in this study, consisted of (1) aged 18-21 years, (2) not trained (athletes) and did not have a schedule of routine sports activities, and (3) willing to agree to informed consent. The exclusion criteria in this study, consisted of (1) having an open sore on the gastrocnemius muscle, (2) having impaired heat and cold sensibility, (3) having cardiac and respiratory disorders (coronary heart, heart valve disorders, heart rhythm disturbances, pulmonary TB, pneumonia, emphysema, asthma, bronchitis, ARI, etc.), and (4) consumption of pain-reducing drugs in the last 24 hours (NSAIDs, opioid drugs, paracetamol, mefenamic acid, etc.). The drop out criteria that caused the subject to be excluded from the research process, namely (1) the subject did not do exercises to cause DOMS, (2) the subject did not complete the treatment program, and (3) the subject received treatment other than ice packs.

The measuring instrument used in this study was a visual analogue scale (VAS) to describe the intensity of pain after DOMS induction. VAS is a pain measuring instrument in the form of a horizontal line $100 \mathrm{~mm}$ long, represented in a range of 0 to 100 in millimeters. At the left end of the line written no pain (no pain) and the right end of the line written worst imaginable pain (unbearable pain).

The independent variable in this study was a cold compress with a duration of 15 minutes, while the dependent variable was DOMS pain in the gastrocnemius muscle.

The first step of the implementation of this research was to explain the implementation of the research and ask for approval of the research subject through informed consent. In the second step, subjects received exercises with ismoteric and eccentric muscle contraction types before receiving treatment. This exercise was a step up-step down to induce DOMS. The third step was at 24 hours after exercise, pain intensity measurement was carried out with VAS as pre-test data. The fourth step, the experimental group was given therapy with cold compresses for 15 minutes in the gastrocnemius muscle. The fifth step was to measure the intensity of pain as post-test data. Measurements were carried out 24 hours post-treatment as post-test I data and 48 hours post-treatment as post-test II data. The last step was to process the research data that has been collected.

\section{RESULTS}

a) The subjects in this study were 24 physiotherapy students at the Health Polytechnic of Surakarta. Based on gender, the distribution of subjects was 14 women $(58,3 \%)$ and 10 men $(41,7 \%)$. The results of the lavene-test $(\mathrm{p}$-value $=1,000)$ showed that the data is homogeneous (table 1).

TABLE I. SUBJECT CHARACTERISTICS BY GENDER

\begin{tabular}{ccc}
\hline \multirow{2}{*}{ Gender } & The Experimental Group & The Control Group \\
\cline { 2 - 3 } & $\mathbf{n}$ & $\mathbf{n}$ \\
\hline Women & $7(58,3 \%)$ & $7(58,3 \%)$ \\
Men & $5(41,7 \%)$ & $5(41,7 \%)$ \\
Total & $12(100 \%)$ & $12(100 \%)$ \\
\hline Levene-test & & \\
P-value & & \multirow{2}{*}{1,000} \\
\hline
\end{tabular}

Fig. 1. Example of a figure caption. (figure caption)

The number of subjects in this study were 24 people, so that the normality test of the data used the saphiro-wilk test. The results of the statistical test showed $p$-value $>0,05$ then it was stated that the data was normally distributed (table 2)

TABLE II. NORMALITY DATA

\begin{tabular}{lcc}
\hline \multicolumn{1}{c}{ Pain } & The Experimental Group & $\begin{array}{c}\text { The Control } \\
\text { Group }\end{array}$ \\
\hline Pre-test & 0,263 & 0,995 \\
Post-test I & 0,661 & 0,810 \\
Post-test II & 0,661 & 0,290 \\
\hline
\end{tabular}

Evaluation in this study was carried out by measuring the intensity of pain using the VAS about 3 times. The first measurement was carried out after DOMS pain appeared (before the cold compress treatment). The second measurement was carried out 24 hours after the cold compress treatment. While the third measurement was carried out 48 hours after the cold compress treatment (table 3 ). 
TABLE III. PAIN MEASUREMENT DATA WITH VAS

\begin{tabular}{ccccccc}
\hline \multirow{2}{*}{$\begin{array}{c}\text { Pain } \\
\text { Intensity }\end{array}$} & \multicolumn{3}{c}{ The Experimental } & \multicolumn{3}{c}{ The Control Group } \\
\cline { 2 - 7 } & $\begin{array}{c}\text { Pre- } \\
\text { test }\end{array}$ & $\begin{array}{c}\text { Post- } \\
\text { test I }\end{array}$ & $\begin{array}{c}\text { Post- } \\
\text { test II }\end{array}$ & $\begin{array}{c}\text { Pre- } \\
\text { test }\end{array}$ & $\begin{array}{c}\text { Post- } \\
\text { test I }\end{array}$ & $\begin{array}{c}\text { Post- } \\
\text { test II }\end{array}$ \\
\hline Minimum & 42 & 30 & 20 & 40 & 51 & 19 \\
Maximum & 51 & 37 & 27 & 51 & 61 & 27 \\
Mean & 45,17 & 33,50 & 23,50 & 45,00 & 55,33 & 22,25 \\
Standard & 2,588 & 2,276 & 2,276 & 2,923 & 2,807 & 2,768 \\
Deviation & & & & & & \\
\hline
\end{tabular}

The results of the repeated measures anova test showed a significant reduction in DOMS pain at 24 hours and 48 hours after the treatment in the experimental group ( $p$-value $=0,000$ ). It also happened in the control group ( $\mathrm{p}$-value $=0,000$ ) as shown in the table 4.

TABLE IV. THE RESULT OF THE REPEATED MEASURES ANOVA TEST

\begin{tabular}{llll}
\hline & & p-value & Mean \\
\hline $\begin{array}{l}\text { The } \\
\text { Experimental } \\
\text { Group }\end{array}$ & Pre test - post test I & 0,000 & 11,667 \\
& & & \\
& Post test I - post test II & 0,000 & 10,000 \\
& Pre test - post test II & 0,000 & 21,667 \\
\hline \multirow{2}{*}{$\begin{array}{l}\text { The Control } \\
\text { Group }\end{array}$} & Pre test - post test I & 0,000 & $-10,333$ \\
& Post test I - post test II & 0,000 & 33,083 \\
& Pre test - post test II & 0,000 & 22,750 \\
\hline
\end{tabular}

The results of the one-way anova test (table 5) showed that there were differences between the experimental group and the control group in post-test I $(p$-value $=0.000)$ and no differences between groups in post-test II ( $\mathrm{p}$-value $=0.438$ ). The differences effect of pre and post-test I in the experimental group showed a mean value of 11,667, while the control group showed a mean value of $-10,333$ (table 4). This indicates that cold compress was more influential in reducing DOMS pain in 24 hours after treatment than without treatment.

TABLE V. THE RESULT OF ONE WAY ANOVA TEST

\begin{tabular}{lll}
\hline \multicolumn{1}{c}{ Criteria } & \multicolumn{1}{c}{ p-value } & \multicolumn{1}{c}{ Description } \\
\hline Post test I & 0,000 & There is a significant difference \\
Post test II & 0,438 & $\begin{array}{l}\text { There is no significant } \\
\text { difference }\end{array}$ \\
\hline
\end{tabular}

\section{DISCUSSION}

Based on gender, the distribution of subjects was 14 women $(58,3 \%)$ and $10 \mathrm{men}(41,7 \%)$. The results of the lavene-test $(\mathrm{p}$-value $=1,000)$ showed that the data is homogeneous (table 1).

The results of the study by Clegg et al., (2011), stated that gender affects the absorption of temperature in the cold modality due to differences in the composition of adipose tissue between women and men. Women have adipose tissue structure with a structure that can enlarge and store more fat tissue, while adipose structure in men cannot enlarge. According to Konrath et al., (1996) dan Murray \& Cardinale, (2015), fat tissue is a temperature insulator that can inhibit cold penetration.

In this study, to observe the decrease in DOMS pain in the experimental group, not only by observing the repeated measures ANOVA test results, but also by observing the difference in the mean value in the experimental group and the control group. In the control group, DOMS pain appeared in the first 24 hours, then increased at 48 hours, and decreased at 72 hours. These results are supported by the results of research by Cheung (2003), Veqar (2013), and Muray \& Cardinale (2015), pain in DOMS physiologically will appear in the first 12 hours, reach a peak at 24-72 hours, then decrease and will disappear after 5-7 days.

In post test I, which is 24 hours after the cold compress treatment, the results of the repeated measure ANOVA test in the experimental group were p-value 0.000 . It was concluded that an ice pack with a duration of 15 minutes had an effect on reducing DOMS pain. The differences effect of pre and post-test I in the experimental group showed a mean value of 11,667 , while the control group showed a mean value of 10,333 . This indicates that cold compress was more influential in reducing DOMS pain in 24 hours after treatment than without treatment.

This result is in accordance with the research conducted by Malmir et al. (2017), who conducted experiments on 16 subjects with ice bag treatment and 10 subjects in the control group without treatment. In this study, observations were made on DOMS pain intensity which was measured using VAS, range of motion (ROM), and triple hop test distance. Both groups were given high-intensity eccentric exercise to develop DOMS. The treatment group received an ice bag for 10-20 minutes. This study found that only the ice bag group could affect the level of DOMS pain reduction at 24 hours after the intervention.

In a meta-analysis conducted by Hohenauer et al. (2015) compared therapy using cold modalities, therapies other than cold modalities, and recovery after exercise. Based on 36 articles, 27 articles showed that cold therapy with a duration of 10-15 minutes had a significant effect on reducing DOMS pain compared to the control group without treatment within 48 hours after treatment.

Cold compresses with a duration of 10-20 minutes will have the effect of decreasing local temperature and controlling the pain effect of the inflammatory process. Pain is controlled through the tissue response to cold temperatures (Bruno et al., 2016). Cold compresses cause local and physiologic vasoconstriction of arterioles and venules. This vasoconstriction is 
influenced by autonomic nerve activity in the arterioles and the activity of the hormone epinephrine. In addition to vasoconstriction, there is blood transport and a decrease in plasma accumulation (Malanga, 2015). Vasoconstriction in arterioles causes a narrowing of arteriolar diameter $7 \%-14 \%$ compared to the initial state. Narrowing of arteriolar diameter that will affect blood flow and transport of inflammatory mediators (Bruno et al., 2016).

When the body is exposed to cold temperatures, the body will issue a neurohormonal response that affects pain reduction. After the cold temperature stimulates the adrenoreceptors, the hormones epinephrine and norepinephrine are activated. Epinephrine will stimulate vasoconstriction while norepinephrine will stimulate an increase in the threshold for excitatory polymodal nociceptors to decrease nerve conductivity (Bruno et al., 2016).

In addition, exposure to cold temperatures will result in thermal neuropraxia, namely neuropraxia which results in a decrease in nerve conductivity (Malanga, 2015). After exposure to cold temperatures between 10-20 minutes the nerve conductivity will decrease between $20 \%-30 \%$. This decrease in excitatory threshold and decrease in nerve conductivity also plays a role in reducing DOMS pain after being given an ice pack intervention (Bruno et al., 2016).

In post test II, which is 48 hours after the cold compress treatment, the results of the repeated measure ANOVA test in the experimental group were p-value 0.000 . It was concluded that an ice pack with a duration of 15 minutes had an effect on reducing DOMS pain. The results of this study showed a significant reduction in pain in all groups. But to draw a conclusion whether there is an effect of giving ice compresses to the treatment group, a one-way ANOVA test must be carried out to compare the average difference in DOMS pain reduction between the treatment group and the control group.

The results of the one-way anova test showed that there were differences between the experimental group and the control group in post-test I and no differences between groups in post-test II.

The finding that compress treatment had no effect on reducing DOMS pain at 48 hours after intervention was in accordance with Broath's (2014) study, on the effect of giving cold modalities compared to the effect of placebo. This study was conducted on 30 subjects who were divided into 3 groups, 10 subjects in the intervention group with ice packs, 10 subjects in the ice bath intervention group, and 10 subjects in the placebo intervention group. The results showed that ice packs more effective compared to the placebo group in the first 24 hours. But after observing at 48 hours, ice packs did not show any difference with the placebo group. These results were based on the fact that in the first 24 hours there was no increase in neutrophils and bradykinin in blood plasma in the ice pack group when compared to the placebo group. However, after 48 hours of intervention, plasma neutrophil and creatine kinase levels showed relatively similar results between the ice pack group and the placebo group. Veqar (2013), stated that an increase in neutrophils and bradykinin in blood plasma is a sign of muscle damage.

According to Herrera et al., (2010), the physiological effects of ice packs in the form of vasoconstriction in arterioles and venules trigger in a decrease the sensitivity of nerve which will only last for 24 hours and decrease after that. In addition, according to Higgins et al., dalam Hohenauer et al., (2015), stated that giving a cold compress for 15 minutes can affect levels of reactive oxygen active (ROS) and damage associated molecular pattern (DAMP). When DOMS occurs, there will be an increase in ROS and DAMP (Wigus et al., 2013). After being given a cold compress for 15 minutes resulted in a significant decrease in ROS and DAMP in the first 24 hours. However, after further observations, it will increase again at 48 hours after giving cold intervention.

The limitations of this study were that room temperature measurements were not controlled, and evaluation was only carried out for 48 hours after treatment, not until DOMS pain disappeared.

The clinical implication of this study is that ice packs can be applied to reduce delayed onset muscle soreness (DOMS) pain in the gastrocnemmius muscle with a recommended compress duration of 15 minutes.

\section{CONCLUSION}

All subjects selected were given step up-step down treatment to induce DOMS. After that, 12 people were given cold compress treatment for 15 minutes and 12 people were not treated. The results of this study were evaluated by measuring the intensity of pain using VAS. It was concluded that cold compress for 15 minutes had a significant effect in reducing the intensity of DOMS pain, especially in 24 hours after treatment.

\section{REFERENCES}

[1] Akley, E. L. T. O., Ardeiro, R. A. B. P., \& Owell, J. O. W. P. (2013). The Effects Of Multiple Daily Applications Of Ice To The Hamstrings On Biochemical Measures, Signs, And Symptoms Associated With Exercise- Induced Muscle Damage. 27(10), 2743-2751.

[2] Bijur, P. E., Silver, W., \& Gallagher, E. J. (2001). Reliability of the Visual Analog Scale for Measurement of Acute Pain. 8(12), 1153-1157

[3] Bruno, F., Geremia, J., \& Baroni, B. M. (2016). Effects of cryotherapy methods on circulatory, metabolic, inflammatory and neural properties : a systematic review. 29(June), 389-398.

[4] Cheung, K., Hume, P. A., \& Maxwell, L. (2003). Delayed Onset Muscle Soreness Treatment Strategies and Performance 
Factors. 33(2), 145-164. https://doi.org/0112-1642/03/0002$0145 / \$ 30.00 / 0$

[5] Contrò, V., Mancuso, E. P., \& Proia, P. (2016). Delayed onset muscle soreness (DOMS) management: present state of the art. 3(23), 121-127.

[6] Dowlati, Y., Herrmann, N., Swardfager, W., Liu, H., Sham, L., Reim, E. K., \& Lanctôt, K. L. (2010). A Meta-Analysis of Cytokines in Major Depression. BPS, 67(5), 446-457. https://doi.org/10.1016/j.biopsych.2009.09.033.

[7] Hall, J. E. (2016). Textbook of Medical Physiology (Thirteenth). Philadelphia: Elsivier.

[8] Hastono, sutanto priyo. (2006). Analisis Data. Jakarta: universitas Indonesia.

[9] Hohenauer, E., Taeymans, J., Baeyens, J., \& Clarys, P. (2015). The Effect of Post-Exercise Cryotherapy on Recovery Characteristics : A Systematic Review and Meta-Analysis. 122. https://doi.org/10.1371/journal.pone.0139028.

[10] Herrera, E., Sandoval, M. C., Diana, M., \& Salvini, T. F. (2010). Research Report Motor and Sensory Nerve Conduction Are Affected Differently by Ice Pack, Ice Massage, and Cold Water. American Physical Therapy Association. https://doi.org/10.2522/ptj.20090131.

[11] Hough, T. (1902). Erographic Studies in Muscular Soreness. American Physiological Society, 76-92. https://doi.org/https://doi.org/10.1152/ajplega cy.1902.7.1.76.

[12] Hwang, S., Chung, G., Kim, Y. H., \& Park, C. (2019). The Role of Maresins in Inflammatory Pain : Function of Macrophages in Wound Regeneration. International Journal of Molecular Sciences

[13] Janssen, W. J., \& Henson, P. M. (2014). Toxicologic Pathology. (November 2011). https://doi.org/10.1177/0192623311428477.

[14] Kidd, B. L., \& Urban, L. A. (2001). Mechanisms of in ammatory pain. 87(1). https://doi.org/10.1093/bja/87.1.3.

[15] Ma, Y., Zhao, Y., Walker, R. K., \& Berkowitz, G. A. (2013). Molecular Steps in the Immune Signaling Pathway Evoked by Plant Elicitor Peptides: Ca $2+$-Dependent Protein Kinases Nitric Oxide, and Reactive Oxygen Species Are Downstream from the Early Ca $2+$ Signal 1. 163(November), 1459-1471. https://doi.org/10.1104/pp.113.226068

[16] Malanga, G. A., Yan, N., \& Stark, J. (2014). Mechanisms and efficacy of heat and cold therapies for musculoskeletal injury Mechanisms and efficacy of heat and cold therapies for musculoskeletal injury. Postgraduate Medicine, (December), 0. https://doi.org/10.1080/00325481.2015.992719.

[17] Malmir, K., Ghotbi, N., Mir, S. M., \& Moradi, B. (2017). Comparing Effects of Cryotherapy and Transcutaneous Electrical Nerve Stimulation on Signs and Symptoms of Delayed Onset Muscle. (264), 73-80. https://doi.org/10.2174/ 1876386301710010073

[18] Mirawati, D., Sapti, A., \& Leni, M. (2018). Manfaat Ice Compress Terhadap Penurunan Nyeri Akibat Delayed Onset Muscle Soreness ( DOMS ) pada Otot Gastrocnemius. 839845.

[19] Murray, A., \& Cardinale, M. (2015). Cold applications for recovery in adolescent athletes : a systematic review and meta analysis. Extreme Physiology \& Medicine, 1-15. https://doi.org/10.1186/s13728-015-0035-8.

[20] Peaston, R. T., Weinkove, C., Peaston, R. T., \& Weinkove, C. (2004). Measurement of catecholamines and their metabolites. https://doi.org/10. 1258/000456304322664663.

[21] Prihantoro, Y. (2018). Prevalensi, Karakteristik, Dan Penanganan Delayed Onset Muscle Soreness (Doms) Di Unit Kegiatan Mahasiswa (Ukm) Olahraga Universitas Negeri Yogyakarta.

[22] Rang, H. P., Ritter, J. M., Flower, R., Henderson, G. (2014). Chapter 14: Noradrenergic Transmition. Rang \& Dale's
Pharmacology. ElsivierHealt Sciennces. hal. 177-196. ISBN 978-0-7020-5497-6.

[23] Seong, S. (2004). Hydrophobicity: an ancient damageassociated molecular pattern that initiates innate immune responses. Nature Reviews Imunology, 4(June).

[24] Silbergnagl, L. \& Lang N. (2000). Pain in Color Atlas of Pathophysiologi. New York: Thieme. 320-321.

[25] Stedman, R. C., \& Heberlein, T. A. (2008). Human Dimensions of Wildlife: An International Hunting and the heart: Physiological response to seeing, shooting, and bagging game. MacEwan University Libraries, (November 2014), 3741. https://doi.org/10.1080/10871209709359092.

[26] Swenson, C., Sward, L., \& J, K. (1996). Cryotherapy in sports medicine. (6), 193-200.

[27] Veqar, Z. (2013). Causes and Management of Delayed Onset Muscle Soreness : A Review. 55, 13205-13211.

[28] Wajant, H., Pfizenmaier, K., \& Scheurich, P. (2003). Tumor necrosis factor signaling. $45-65$. https://doi.org/10.1038/sj.cdd.4401189.

[29] Woolf, C. J., \& Ma, Q. (2007). Review Nociceptors Noxious Stimulus Detectors. 353-364. https://doi.org/10.1016/j.neuron.2007.07.016.

[30] Zondi, P. C., Rensburg, D. C. J. Van, Grant, C. C., \& Rensburg, A. J. Van. (2015). Delayed onset muscle soreness : No pain, no gain? The truth behind this adage. 57(3), 4-6. 